\title{
Assessment of an accessorized pre-filled syringe for home-administered benralizumab in severe asthma
}

\author{
Gary T Ferguson' \\ Adel H Mansur ${ }^{2}$ \\ Joshua $\mathrm{S}$ Jacobs ${ }^{3}$ \\ Jacques Hebert ${ }^{4}$ \\ Corbin Clawson ${ }^{5}$ \\ Wenli Tao ${ }^{6}$ \\ Yanping $\mathrm{Wu}^{6}$ \\ Mitchell Goldman ${ }^{6}$
}

\section{On behalf of the GREGALE study investigators}

'Pulmonary Research Institute of Southeast Michigan, Farmington Hills, MI, USA; ${ }^{2}$ Department of Respiratory Medicine, Birmingham Heartlands Hospital, University of Birmingham, Birmingham, UK; ${ }^{3}$ Allergy \& Asthma Clinical Research, Walnut Creek, CA, USA; ${ }^{4}$ Clinique Spécialisée en Allergie de la Capitale, Allergie et Immunologie, CHU de Québec, Québec, QC, Canada; ${ }^{5}$ Medlmmune LLC, Gaithersburg, MD, USA;

${ }^{6}$ AstraZeneca, Gaithersburg, MD, USA

This article was published in the following Dove Press journal: Journal of Asthma and Allergy

\begin{abstract}
Background: Patients prefer at-home subcutaneous administration of biologics across different diseases, yet no biologic is approved for at-home use for severe, uncontrolled asthma.

Objective: We assessed at-home functionality, reliability, and performance of an accessorized pre-filled syringe (APFS) for subcutaneous benralizumab administration, an anti-eosinophil monoclonal antibody indicated for add-on maintenance treatment of patients with severe eosinophilic asthma.
\end{abstract}

Materials and methods: Patients ( $\mathrm{N}=116)$ with severe, uncontrolled asthma despite receiving medium- or high-dosage inhaled corticosteroids and long-acting $\beta_{2}$-agonists received up to 5 APFS-administered subcutaneous doses (Weeks $0,4,8,12$, and 16) of benralizumab 30 $\mathrm{mg}$. The first 3 doses were administered at the study sites. The patient/caregiver administered the last 2 doses at home. Endpoints included the percentage of dispensed APFS that were used successfully blood eosinophil counts, Asthma Control Questionnaire 6, and safety.

Results: Nearly all dispensed APFS were successfully used in the clinic and at home (Week 0: 116/116, 100\%; Week 4: 116/117, 99\%; Week 8: 115/115, 100\%; Week 12: 112/114, 98\%; Week 16: 108/109, 99\%). Only 1 APFS malfunctioned out of 573 dispensed. Two at-home administrations were unsuccessful because of patient-use error. One unreturned APFS was recorded as nonfunctional. Mean Asthma Control Questionnaire 6 scores decreased from baseline through all post-baseline time points, and nearly complete depletion of eosinophils was observed at the end of treatment. The most common adverse events were nasopharyngitis, upper respiratory tract infection, headache, and sinusitis. Five patients (4\%) experienced transient mild or moderate injection-site reactions.

Conclusion: The APFS was functional, reliable, and performed equally well in the clinic and at home.

Keywords: biologic, subcutaneous, eosinophil, asthma, treatment, patient preference

\section{Introduction}

Severe asthma occurs in $\sim 10 \%$ of the over 315 million people worldwide affected by the disease. ${ }^{1,2}$ Despite treatment with high-dosage inhaled corticosteroids (ICS) plus long-acting $\beta_{2}$-agonists (LABA), severe asthma often remains uncontrolled placing patients at risk of severe exacerbations. ${ }^{3}$ Eosinophilia is associated with asthma severity, increased exacerbation frequency, impaired lung function, and poor asthma control. ${ }^{4-6}$ Benralizumab (FASENRA ${ }^{\mathrm{TM}}$ ), a humanized, afucosylated, antiinterleukin (IL)-5 receptor $\alpha$ monoclonal antibody, is indicated in the USA and the EU for add-on maintenance treatment of patients with severe eosinophilic asthma. ${ }^{7}$ During Phase III trials, subcutaneous benralizumab $30 \mathrm{mg}$ was well tolerated and
Correspondence: Gary T Ferguson Pulmonary Research Institute of Southeast Michigan, 29255 West 10 Mile Road, Suite A, Farmington Hills, MI, USA Tel + I 2484786806

Fax + I 2484786908

Email garytferguson@msn.com 
significantly reduced annual asthma exacerbation rates and oral corticosteroid use, and improved lung function and disease-specific patient-reported outcomes for patients with blood eosinophil counts $\geq 150$ cells $/ \mu \mathrm{L}^{8-11}$

Patients prefer at-home administration of subcutaneously injected biologics across a variety of therapeutic areas. ${ }^{12,13}$ In part to meet this demand, pre-filled syringes, which have become the delivery system of choice for parenteral administration of biologics, are often accessorized to reduce needle stick injury (e.g., with needle guards) and improve usability (e.g., with enlarged finger flanges). ${ }^{14,15}$ None of the biologics approved for the treatment of severe asthma are approved for at-home use. As an approach to addressing this unmet need, we assessed the functionality, reliability, and performance of an accessorized pre-filled syringe (APFS) used to administer a fixed dose of benralizumab subcutaneously in a health care setting and at home.
Some of the results of this study have been previously reported in the form of an abstract. ${ }^{16}$

\section{Materials and methods}

Study design and study population

GREGALE (NCT02417961; pronounced "grey-gah-ley") was a multicenter, nonrandomized, open-label Phase III trial in the USA and Canada. Patients were screened at 26 centers and received treatment at 24 centers. The study included a 2-week screening period, a site administration treatment period (Weeks 0-8), a home administration treatment period (Weeks 12-16), an end-of-treatment visit (Week 20), and a follow-up visit (Week 28; Figure 1A).

Male and female patients with severe, uncontrolled asthma qualified for the study if they were 18-75 years old and had a body weight of $\geq 40 \mathrm{~kg}$. Evidence of asthma was defined as one of the following: airway reversibility based

A

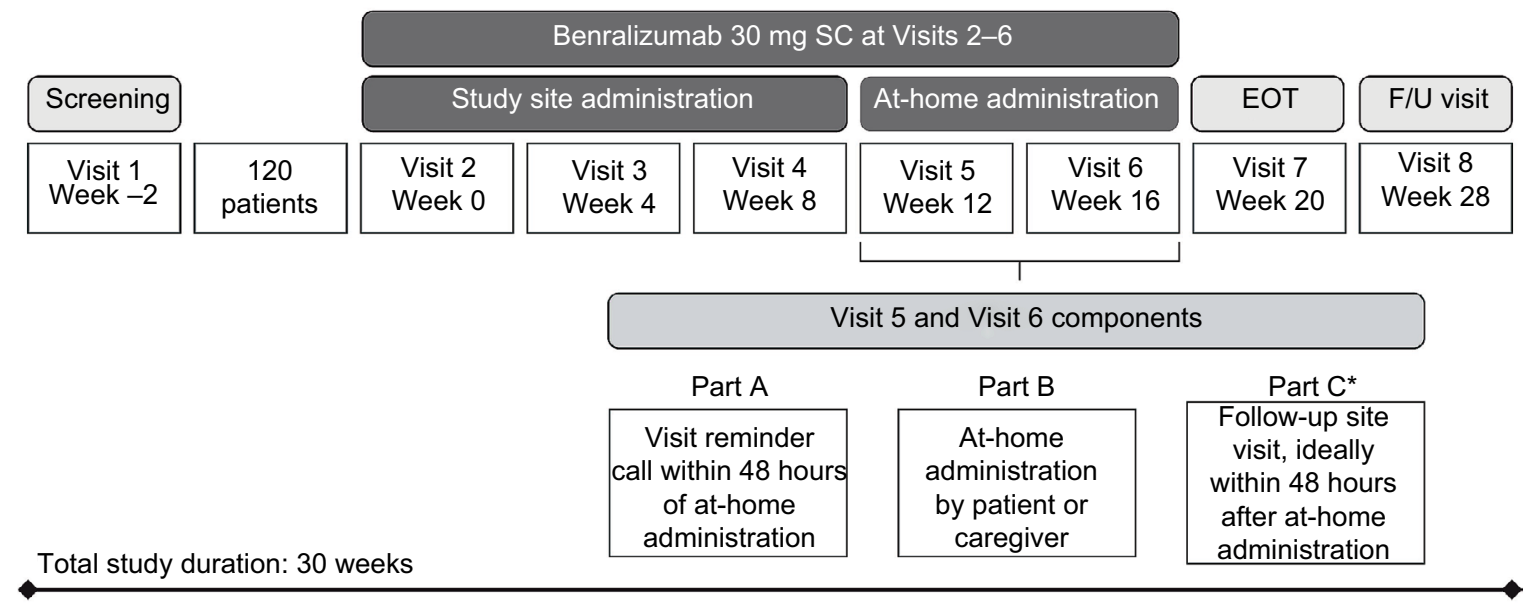

B

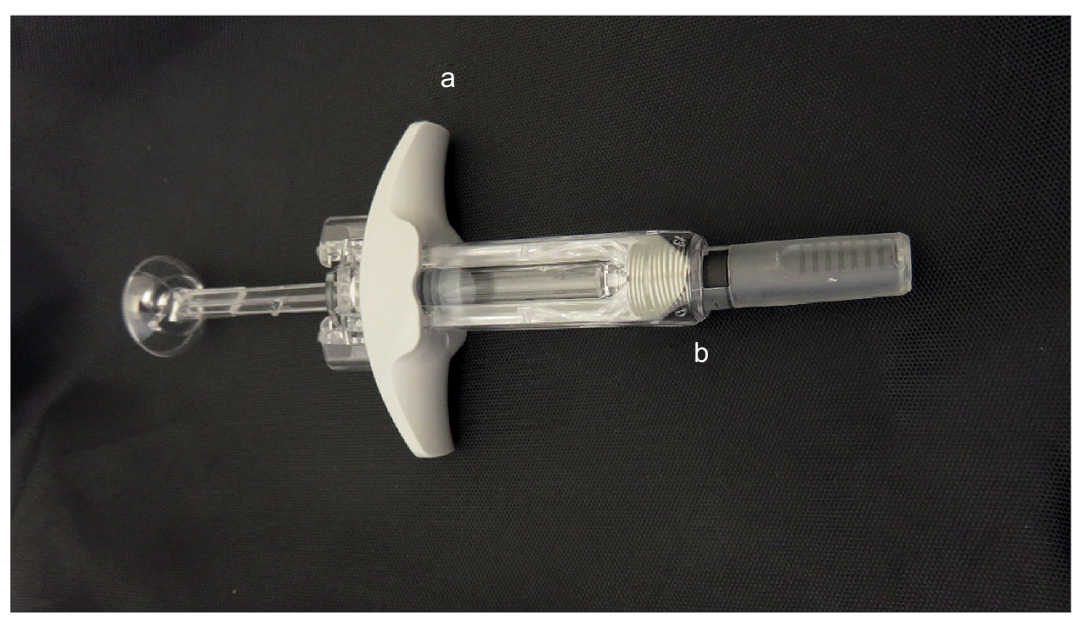

Figure I GREGALE study design (A) and accessorized pre-filled syringe (B).

Notes: *Patients returned used APFS to the study site. $a=$ enlarged finger flanges; $b=$ spring-loaded needle guard.

Abbreviations: APFS, accessorized pre-filled syringe; EOT, end of treatment; F/U, follow-up; SC, subcutaneous. 
on forced expiratory volume in 1 second $\left(\mathrm{FEV}_{1}\right)>12 \%$ and $>200 \mathrm{~mL}$ at screening or the first treatment visit or in the previous year prior to study entry; airflow variability in $\mathrm{FEV}_{1}$ $>20 \%$ between pulmonary function testing in the previous year prior to the first treatment visit; or airflow variability based on $>20 \%$ diurnal variability in peak flow. Patients were required also to have a documented history of current treatment with ICS and LABA, morning prebronchodilator $\mathrm{FEV}_{1}$ of $>50 \%$ predicted at screening or the first treatment visit, and asthma that was documented as not well controlled. Asthma was viewed as not well controlled if the Asthma Control Questionnaire 6 (ACQ-6) score was $\geq 1.5$, the peak flow was $60 \%-80 \%$ of predicted, or $\geq 1$ exacerbation requiring oral or systemic corticosteroids occurred in the previous year. When the ACQ-6 score was $<1.5$, asthma was deemed not well controlled if asthma symptoms occurred $>2$ days/ week, nighttime awakenings occurred $\geq 1$ time/week, or shortacting $\beta_{2}$-agonists (SABA) were used $>2$ days/week, in the 2-4 weeks prior to study entry. Exclusion criteria included clinically important pulmonary diseases other than asthma; a medical disorder that in the opinion of the investigator was not stable and could affect patient safety, study results, or patient completion of trial; and a smoking history of $\geq 10$ pack-years or status as a current smoker. An assessment of whether a disorder would affect a patient or caregiver's ability to administer benralizumab was performed during the supervised on-site training in APFS use.

An independent ethics committee or institutional review board for each study center approved the final study protocol. The approving committees and boards were the Copernicus Group (Durham, NC, USA), the Institutional Review Board Services (Ontario, OTT, Canada), the Hospital Sacre Coeur Comité d'éthique de la recherche (Montreal, QC, Canada), the University of British Columbia Clinical Research Ethics Board (Vancouver, BC, Canada), and the University of Calgary Conjoint Health Research Ethics Board (Calgary, AB, Canada). All patients provided a signed informed consent form prior to study initiation. This study was performed in accordance with the Declaration of Helsinki, the International Council for Harmonisation/Good Clinical Practice guidelines, the applicable regulatory requirements, and AstraZeneca policy on bioethics.

\section{Procedures}

Benralizumab (manufactured by AstraZeneca, Gaithersburg, MD, USA) was administered as a $30 \mathrm{mg} / \mathrm{mL}$ solution in a $1 \mathrm{~mL}$ APFS (Becton Dickinson syringes and accessories were filled, assembled, and packaged by Cook Pharmica LLC, Bloomington, IN, USA; Figure 1B). Patients received benralizumab on study site visits at Weeks 0,4 , and 8 . At Week 0 , benralizumab was administered by the principal investigator. At Week 4, the patient/caregiver was given the option of self-administering benralizumab under the supervision of the principal investigator; and at Week 8, the patient/caregiver performed the injection. At Weeks 12 and 16, the patient/caregiver administered benralizumab at home. For home administration, the patient received the APFS instructions for reference. After each home administration, the patients returned for an on-site visit within 48 hours. Patients filled out a questionnaire to indicate whether the syringe functioned properly and whether the dose was administered successfully with each home administration. Both the questionnaire and the used syringe were returned to the study site after each home administration. The study site returned the APFS used for home administration to the study sponsor for in vitro evaluation of functionality.

\section{Outcomes}

The primary objective was to assess functionality, reliability, and performance of the APFS used to administer benralizumab in the clinic and at home. The primary endpoints were the percentage of dispensed APFS that were used successfully in the clinic and at home, the percentage of malfunctioning APFS at home or in the clinic, and the percentage of returned APFS used to administer at home evaluated as functional. Secondary endpoints assessed benralizumab pharmacokinetics, pharmacodynamics (i.e., eosinophil counts), efficacy (i.e., the change in mean ACQ-6 score from baseline), immunogenicity, and safety. Mild, moderate, and severe adverse events (AEs) were recorded throughout the study. Serious AEs, as defined by the US Food and Drug Administration, were recorded, and the likelihood that a serious AE was or was not related to benralizumab treatment was adjudicated by the principal investigator at each study site.

Successful benralizumab administration with the APFS was defined as a completed injection, a "Yes" answer to all questionnaire inquiries, and a satisfactory result in the in-vitro examination of the device post use. Evaluation of returned APFS for function was based on questionnaire responses, visual inspection, and functional testing. Serum benralizumab concentration and the presence of serum anti-drug antibodies (ADA) were measured predose at Weeks 0 and 8 and at Weeks 20 and 28 with validated bioanalytical methods. Blood eosinophil counts were measured as part of the routine hematology assessments performed at Weeks 0, 20, and 28.

The ACQ-6 is a shortened version of the ACQ that assesses asthma symptoms (nighttime awakenings, symptoms on waking, activity limitation, shortness of breath, and wheezing) and SABA use while omitting the FEV 
measurement from the original ACQ score. Patients were asked to recall their experiences during the previous week and to score each of the questions on a 7-point scale ranging from 0 (totally controlled) to 6 (severely uncontrolled). The overall score was calculated as the mean response to all questions. Mean scores of $\leq 0.75$ indicated well-controlled asthma, scores $>0.75$ and $<1.5$ indicated partly controlled asthma, and scores $\geq 1.5$ indicated poorly controlled asthma. ${ }^{17}$ Improvement in asthma control is reflected by a decrease in ACQ-6 score. Individual ACQ-6 score changes of $\geq 0.5$ were considered to be clinically meaningful.

\section{Statistical analysis}

No hypotheses were tested statistically. An estimated sample size of 120 patients was based on the successful enrollment of 100 patients, with adjustment to account for an estimated dropout rate of $17 \%$ (20 patients). Summary data were presented in tabular format, and categorical data were summarized by the number and percentage of patients in each category. Continuous data were summarized by descriptive statistics, including N, mean, standard deviation, median, and range. The change from baseline was computed as baseline value subtracted from visit value. If either value was missing, the change from baseline was set to missing.

All analyses were performed by using the full analysis set, except the pharmacokinetic analysis, which used the pharmacokinetic analysis set. The full analysis set included all patients receiving benralizumab, irrespective of their protocol adherence and continued participation in the study. Patients who had at least 1 quantifiable serum benralizumab observation after the first dose were included in the pharmacokinetic analysis data set. An independent data safety monitoring board oversaw the safety and other clinical trial data at regular intervals. All data were analyzed with SAS System version 9.2 (SAS Institute Inc., Cary, NC, USA).

\section{Results}

\section{Patient disposition}

Patients received treatment at 24 centers in the USA and Canada. Out of 116 patients who received treatment with benralizumab, 7 patients $(6 \%)$ discontinued treatment. Two of these 7 patients discontinued treatment before receiving their first at-home dose. The reasons for discontinuation of treatment were AE (3 patients [2.6\%]), patient decision (2 patients [1.7\%]: 1 before and 1 after the start of the at-home treatment period), severe noncompliance to protocol (1 patient $[0.9 \%]$ had emergency travel preventing administration of the last dose of benralizumab), and development of study-specific discontinuation criteria (1 patient [0.9\%] had an asthma exacerbation between Weeks 12 and 16). Four patients $(3.4 \%)$ withdrew from the study. The reasons for withdrawal were patient decision (2 patients [1.7\%]), AE (1 patient [0.9\%]), and patient lost to follow up (1 patient $[0.9 \%])$.

\section{Demographics and baseline clinical characteristics}

Demographics and baseline clinical characteristics were representative of the intended target population of patients with uncontrolled asthma (Table 1). Patients had a median age of 49 years (range: 18-75 years), and a mean body mass

Table I Demographics and baseline clinical characteristics

\begin{tabular}{|c|c|}
\hline Characteristic & Benralizumab $(\mathrm{N}=1 \mid 6)$ \\
\hline Age (years), median (range) & $49(18-75)$ \\
\hline \multicolumn{2}{|l|}{ Age group (years), n (\%) } \\
\hline$\geq 18$ to $<50$ & $60(52)$ \\
\hline$\geq 50$ to $<65$ & $43(37)$ \\
\hline$\geq 65$ & $13(11)$ \\
\hline \multicolumn{2}{|l|}{ Sex, n (\%) } \\
\hline Male & $52(45)$ \\
\hline Female & $64(55)$ \\
\hline \multicolumn{2}{|l|}{ Race, n (\%) } \\
\hline White & $94(8 \mathrm{I})$ \\
\hline Black or African-American & $16(14)$ \\
\hline Asian & $4(3)$ \\
\hline Other & $2(2)$ \\
\hline \multicolumn{2}{|l|}{ Ethnic group, n (\%) } \\
\hline Hispanic or Latino & $9(8)$ \\
\hline Not Hispanic or Latino & $107(92)$ \\
\hline BMI $\left(\mathrm{kg} / \mathrm{m}^{2}\right)$, mean $(\mathrm{SD})$ & $32.0(8.1)$ \\
\hline $\begin{array}{l}\text { Blood eosinophil count (cells/ } \mu \mathrm{L}) \text {, } \\
\text { median (IQR) }\end{array}$ & $250(175-430)$ \\
\hline $\mathrm{FEV}$, prebronchodilator(L), mean (SD) & $2.3 I I(0.784)$ \\
\hline $\begin{array}{l}\mathrm{FEV} \text {, prebronchodilator (\% predicted } \\
\text { normal), mean (SD) }\end{array}$ & $70.8(15.4)$ \\
\hline $\begin{array}{l}\mathrm{FEV}_{\mathrm{I}} / \mathrm{FVC} \text { prebronchodilator (\%), } \\
\text { mean (SD) }\end{array}$ & $73(11)$ \\
\hline FEV , reversibility (\%), mean (SD) & $15.9(14.2)$ \\
\hline $\begin{array}{l}\text { Time since asthma diagnosis (years), } \\
\text { median (range) }\end{array}$ & $24.4(0.9-65.6)$ \\
\hline $\begin{array}{l}\text { Exacerbations in the previous } 12 \text { months, } \\
\text { mean (SD), } n(\%)\end{array}$ & $0.6(0.8)$ \\
\hline 0 & $71(6 I)$ \\
\hline 1 & $29(25)$ \\
\hline 2 & $13(11)$ \\
\hline 3 & $3(3)$ \\
\hline ACQ-6 score, mean (SD) & $2.14(0.81)$ \\
\hline Diagnosis of allergic rhinitis, $n$ (\%) & $96(83)$ \\
\hline Nasal polyps, n (\%) & $18(16)$ \\
\hline OCS use, n (\%) & $2(2)$ \\
\hline
\end{tabular}

Abbreviations: ACQ-6, Asthma Control Questionnaire 6; FEV , forced expiratory volume in I second; FVC, forced vital capacity; IQR, interquartile range; OCS, oral corticosteroid. 
index (BMI) of $32.0 \mathrm{~kg} / \mathrm{m}^{2}$ (SD: $8.1 \mathrm{~kg} / \mathrm{m}^{2}$ ). Most patients were white $(81 \%)$, and more than half of the patients were female $(55 \%)$. The median time since asthma diagnosis was 24.4 years (range: 0.9-65.6). Mean prebronchodilator $\%$ predicted normal $\mathrm{FEV}_{1}$ was $71 \%$ (SD: 15\%), which was slightly greater than expected for patients with severe asthma. Mean baseline ACQ-6 score was 2.14 (SD: 0.81), which was consistent with expected values for patients who have uncontrolled asthma. The mean number of exacerbations in the past 12 months was 0.6 (SD: 0.8 ), with the majority of patients $(61 \%)$ having none. Other key respiratory diseases included allergic rhinitis ( $83 \%$ of patients) and nasal polyposis ( $16 \%$ of patients).

\section{Functionality, reliability, and performance of the APFS}

Benralizumab was successfully administered to $100 \%$ of patients at Weeks 0 (116 patients), 4 (116 patients), and 8 (115 patients), 98\% of patients at Week 12 (112/114 patients), and $99 \%$ of patients at Week 16 (108/109 patients). Nearly all dispensed APFS were successfully used in the clinic and at home (Week 0: 116/116, 100\%; Week 4: 116/117, 99\%; Week 8: 115/115, 100\%; Week 12: 112/114, 98\%; Week 16: 108/109, 99\%; Figure 2). Of 573 dispensed APFS, only 1 malfunctioned. The malfunction occurred at Week 4 during the period in which benralizumab was administered at the clinical site. The person performing the injection prematurely activated the safety needle guard, rendering the APFS unusable. After evaluation of the manufacturing records and examination of the APFS, it was determined that the malfunction was caused by incorrect assembly of the device by the commercial operator. The APFS was replaced, and benralizumab was successfully administered.

Three APFS were returned as nonfunctional during the period in which benralizumab was administered at home by the patient or caregiver. Two of the 3 devices were nonfunctional because of patient-use error. At Week 12, one patient did not remove the syringe cap on the APFS but did correctly use the replacement device. The second patient did not administer the full dose of benralizumab at Week 16 because the patient sneezed during APFS use. One APFS received a default outcome of nonfunctional because it was not returned.

\section{Benralizumab pharmacokinetics, pharmacodynamics, efficacy, and immunogenicity}

Geometric mean serum benralizumab concentrations were $1032 \mathrm{ng} / \mathrm{mL}$ at Week $8,802 \mathrm{ng} / \mathrm{mL}$ at Week 20 , and $56 \mathrm{ng} / \mathrm{mL}$

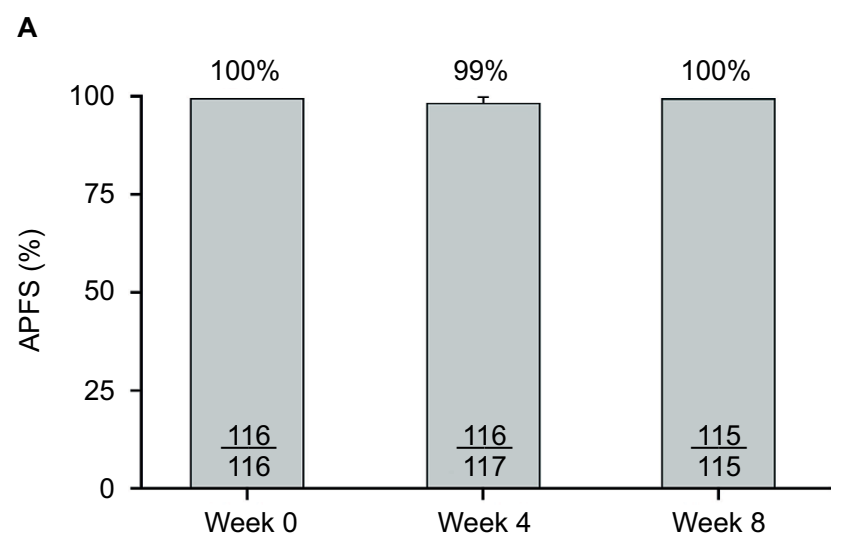

B

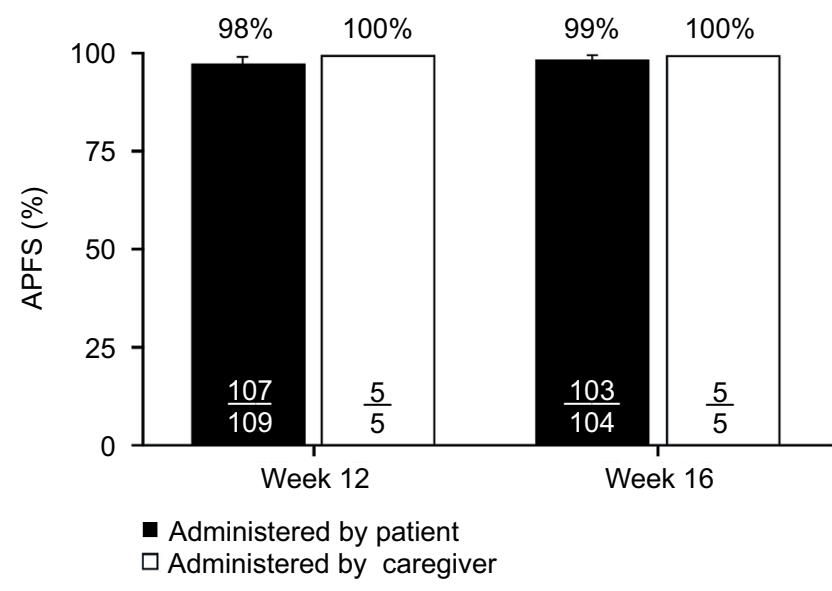

Figure 2 Percentage of dispensed APFS that were successfully used at the clinical site $(\mathbf{A})$ and at home (B).

Notes: Successful administration was defined as a completed injection, an answer of "Yes" to all the 5 questions in the questionnaire, and passing results in visual inspection and function tests of the APFS after use.

Abbreviation: APFS, accessorized pre-filled syringe.

at Week 28 (Table 2). The potent anti-IL-5 receptor $\alpha$ properties of benralizumab were evident in that nearly complete depletion of blood eosinophil count occurred by Week 20, and it was maintained to Week 28 (Figure 3). By the end of treatment (Week 20), the mean ACQ-6 score decreased compared with the baseline value (Table 3, Figure 4). ACQ-6 score decreased $\geq 0.5$ for 66 patients (57\%), representing an improvement in asthma control.

Two patients (2\%) were ADA-positive at baseline only, another $2(2 \%)$ were positive at all time points but without boosted ADA titers (defined as $>4$-fold increase), and 13 (11\%) developed ADAs after the treatment began. Thus, the prevalence and incidence of ADAs were 15\% (17 of 116 patients) and $11 \%$ (13 of 116), respectively. The presence of neutralizing antibodies did not alter the pharmacodynamics of benralizumab, as demonstrated by comparable eosinophil depletion for ADA-positive and ADA-negative patients (Figure 3). 
Table 2 Serum concentrations of benralizumab

\begin{tabular}{|c|c|c|c|c|}
\hline \multirow{2}{*}{$\begin{array}{l}\text { Pharmaco- } \\
\text { kinetic } \\
\text { parameter }\end{array}$} & \multicolumn{4}{|l|}{ Visits } \\
\hline & $\begin{array}{l}\text { Baseline } \\
(n=|| 5)\end{array}$ & $\begin{array}{l}\text { Week } 8 \\
(n=I \mid 3)\end{array}$ & $\begin{array}{l}\text { Week } 20 \\
(n=I I I)\end{array}$ & $\begin{array}{l}\text { Week } 28 \\
(n=I I I)\end{array}$ \\
\hline $\mathrm{n}<\mathrm{LLOQ}$ & 114 & 0 & $4^{a}$ & 19 \\
\hline $\begin{array}{l}\text { Geometric mean, } \\
\mathrm{ng} / \mathrm{mL} \text { (CV [\%]) }\end{array}$ & BLQ & $1032(54)$ & $802(267)$ & $56(500)$ \\
\hline $\begin{array}{l}\text { Arithmetic mean, } \\
\mathrm{ng} / \mathrm{mL} \text { (SD) }\end{array}$ & BLQ & II 47 (478) & 1205 (658) & $140(134)$ \\
\hline $\begin{array}{l}\text { Median, } \mathrm{ng} / \mathrm{mL} \\
\text { (range) }\end{array}$ & $\begin{array}{l}\text { BLQ } \\
(<L L O Q-13)\end{array}$ & $\begin{array}{l}1160 \\
(154-2740)\end{array}$ & $\begin{array}{l}\text { II } 40 \\
(<L L O Q- \\
2820)\end{array}$ & $\begin{array}{l}104 \\
(<L L O Q- \\
579)\end{array}$ \\
\hline
\end{tabular}

Notes: aAntidrug antibodies were persistently elevated in all 4 patients, which may have contributed to the lower than expected serum concentrations of benralizumab. Abbreviations: BLQ, below limit of quantification; CV, coefficient of variation; LLOQ, lower limit of quantification $(3.86 \mathrm{ng} / \mathrm{mL})$.

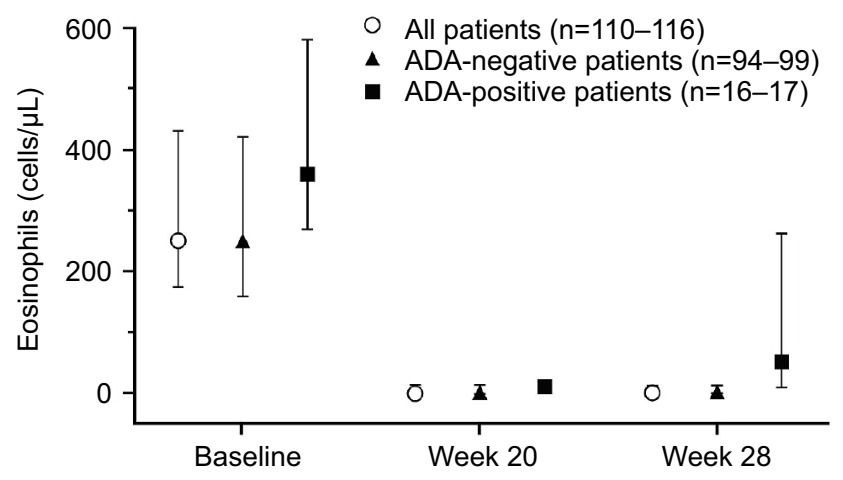

Figure 3 Median eosinophil counts over time.

Notes: Error bars represent the first and third quartiles.

Abbreviation: ADA, antidrug antibody.

Table 3 Asthma control status based on ACQ-6 scores at baseline and end of treatment

\begin{tabular}{ll}
\hline Asthma control status & $\begin{array}{l}\text { Benralizumab } \\
\mathbf{( N = I ~ I 6 ) ~}\end{array}$ \\
\hline Baseline, $\mathrm{n}(\%)$ & \\
$\quad \leq 0.75$ (well-controlled) & $5(4)$ \\
$>0.75$ to $<1.5$ (partly controlled) & $18(16)$ \\
$\geq 1.5$ (not well-controlled) & $93(80)$ \\
Missing & $0(0)$ \\
End of treatment (week 20), $\mathrm{n}(\%)$ & \\
$\leq 0.75$ (well-controlled) & $30(26)$ \\
$>0.75$ to $<1.5$ (partly controlled) & $27(23)$ \\
$\geq 1.5$ (not well-controlled) & $54(47)$ \\
Missing & $5(4)$ \\
\hline
\end{tabular}

Abbreviation: ACQ-6, Asthma Control Questionnaire 6.

\section{Safety of subcutaneous benralizumab $30 \mathrm{mg}$ administered via an APFS}

Benralizumab $30 \mathrm{mg}$ was well tolerated, and the mean duration of exposure of the drug was 110 days (range: 29-124) for all the 116 patients. A total of 19 patients (16\%) had 1

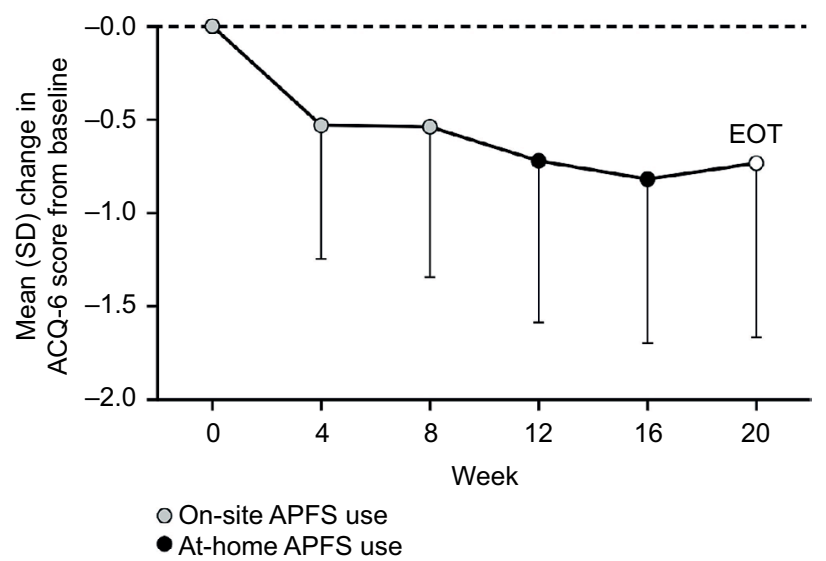

Figure 4 Mean (SD) change in ACQ-6 score from baseline.

Abbreviations: ACQ-6, Asthma Control Questionnaire 6; APFS, accessorized pre-filled syringe; EOT, end of treatment.

Table 4 Most common AEs reported ( $>5 \%$ of patients) during the study period

\begin{tabular}{ll}
\hline Adverse event & Benralizumab $\mathbf{3 0 ~} \mathbf{~ m g}(\mathbf{N}=1$ l 6) \\
\hline Patients with $\geq I A E^{a}$ & $77(66)$ \\
Nasopharyngitis & $16(14)$ \\
Upper respiratory tract infection & $13(11)$ \\
Headache & $6(5)$ \\
Sinusitis & $6(5)$ \\
\hline
\end{tabular}

Notes: apatients with $>\mid$ event in the same category were counted only once in that category, and patients with events in $>$ I category were counted once in each of those categories.

Abbreviation: $\mathrm{AE}$, adverse event.

asthma exacerbation, 1 patient ( $1 \%$ ) had 2 exacerbations, and no patients had an exacerbation that required hospitalization. Of the 116 patients, 77 (66\%) had at least $1 \mathrm{AE}$ during the study. Most AEs were mild to moderate. The most common AEs, which were reported for $>5 \%$ of patients, were nasopharyngitis, upper respiratory tract infection, headache, and sinusitis (Table 4). Systemic AEs that the investigator considered to be related to benralizumab administration were nausea (2 patients [2\%]) and headache, acute sinusitis, arthralgia, dizziness, and fatigue ( 1 patient $[1 \%]$ each).

Injection-site reactions, which occurred in 5 patients (4\%), were considered to be nonserious and mild or moderate, and resolved within 1-15 days. These included injection-site hemorrhage $(n=2[2 \%])$, erythema $(n=1[1 \%])$, induration $(\mathrm{n}=1[1 \%])$, and pain $(\mathrm{n}=1[1 \%])$. No injection-site reaction led to discontinuation of the treatment. No AEs related to device malfunction were reported during the study.

Three patients $(3 \%)$ discontinued benralizumab treatment because of AEs. By week 8, 1 patient had discontinued treatment and had withdrawn from the study because of acute sinusitis. From Weeks 12-16, 2 patients discontinued 
treatment because of nausea and dizziness $(n=1)$ and moderate urticaria $(n=1)$. The patient who developed urticaria also withdrew from the study. A total of 7 patients $(6 \%)$ reported serious AEs, none of which were related to benralizumab treatment.

\section{Discussion}

The GREGALE study was conducted to evaluate the functionality, reliability, and performance of an APFS for subcutaneous administration of benralizumab to patients with severe, uncontrolled asthma. Although patients prefer the convenience of administering subcutaneous biologics in an at-home setting, none of the biologics approved for the treatment of severe asthma are approved for at-home use. Based on our literature review, we believe this study is the first to assess the in-clinic and at-home use of an APFS for subcutaneous administration of a biologic for the treatment of severe, uncontrolled asthma. We found that the device performed equally well in the clinic and at home, and that health care providers, patients, and their caregivers could reliably administer subcutaneous benralizumab.

Nearly all dispensed APFS were successfully used in the clinic and at home. Only 1 of 573 dispensed APFS malfunctioned. In this instance, the spring-loaded needle guard was prematurely activated because of an error in APFS assembly. Two APFS were returned as nonfunctional because of user error ( 1 patient did not remove the needle cap and 1 patient sneezed during injection). One additional APFS was given the default status of nonfunctional because it was not returned and could not be evaluated. Results of this study indicate that health care providers, and the majority of patients and caregivers can be adequately trained to administer subcutaneous benralizumab via an APFS in the clinic and in an at-home setting.

The APFS used in our study is similar to one currently approved for at-home administration of ustekinumab for the treatment of plaque psoriasis. ${ }^{18}$ Both devices contain a pre-filled syringe, which is encapsulated by a needle safety guard. The spring-loaded needle guard is activated by fully depressing the plunger and injecting the entire contents of the syringe. Activation of the needle guard retracts the used needle and prevents needle-stick injury. An additional feature of the APFS used in the GREGALE study is the enlarged finger flanges. These flanges facilitate the user's grip on the device and the application of sufficient force to the plunger to inject a complete dose of benralizumab. There were no reports of needle-stick injuries in our study, and only 1 instance of incomplete injection of benralizumab (the patient sneezed during injection). The device was sufficiently designed to administer benralizumab reliably and be handled safely in the at-home setting.

Pharmacokinetic, pharmacodynamic, and efficacy assessments confirmed that patient and caregiver use of an APFS in an at-home setting was sufficient to achieve benralizumab exposures comparable to those achieved when benralizumab was administered by health care providers at clinical sites. In our study, serum concentrations of benralizumab and improvement in ACQ-6 scores were stable from Week 8 (after the first dose by a health care provider) to Week 20 (after an additional 4 doses, at least 3 of which were administered by the patient/caregiver). Furthermore, the nearly complete depletion of blood eosinophils reported after benralizumab $30 \mathrm{mg}$ injection in other Phase III trials was observed in GREGALE as well..$^{8-10,19}$ A concern of respiratory professionals and primary care providers unfamiliar with at-home use of biologics is the potential for nonadherence to treatment when patients self-administer in an unsupervised setting. This concern is alleviated when one considers the fact that rheumatologists, gastroenterologists, dermatologists, and others have been prescribing at-home biologics for many years. The availability of a readily accessible pharmacodynamic biomarker (blood eosinophil count) means that adherence to treatment should be readily detectable.

The safety profile of APFS-administered benralizumab was comparable to that observed for studies in which benralizumab was administered only by health care providers and at clinical sites. ${ }^{8-10,19}$ Of particular note was that the incidence of injection-site reactions in GREGALE (4\% of patients) was similar to those observed in the 12-week BISE and 28-week ZONDA studies (up to 3\% of patients), and no AEs were related to APFS use. ${ }^{9,19}$ A longer duration study will be needed to assess long-term efficacy and safety of APFS-administered benralizumab in an at-home setting.

Although the approved dosage of benralizumab is body weight agonistic, the mean baseline BMI for the GREGALE population was high $\left(32 \mathrm{~kg} / \mathrm{m}^{2}\right)$. A high BMI is not uncommon for patients with severe, uncontrolled asthma and may reflect population-specific factors such as corticosteroid use of high frequency and dosage. A post-hoc analysis of the combined SIROCCO/CALIMA Phase III data set demonstrated that BMI (stratified by $\leq 35 \mathrm{~kg} / \mathrm{m}^{2}$ or $>35 \mathrm{~kg} / \mathrm{m}^{2}$ ) was not a predictor of benralizumab efficacy. ${ }^{20}$ Thus, we believe the high BMI in the GREGALE study is representative of the target population and was unlikely to influence outcomes. 


\section{Conclusion}

The use of an APFS at home or in the clinic is a well-tolerated and reliable method for administering subcutaneous benralizumab $30 \mathrm{mg}$ as an add-on treatment for patients with severe, uncontrolled asthma. Self-administration or administration by a caregiver at home would provide a complementary option to administration by health care providers and help optimize patient care.

\section{Acknowledgments}

Editorial support was provided by Francis J Golder, BVSc, PhD, of JK Associates, Inc., and Michael A Nissen, ELS, of AstraZeneca. The GREGALE trial was funded by AstraZeneca. The results of this study were presented at the American Thoracic Society 2017 International Conference, May 19-24, 2017, Washington, DC, as a poster presentation. The poster's abstract was published in the American Journal of Respiratory and Critical Care Medicine. The abstract can be found online at http://www.atsjournals. org/doi/abs/10.1164/ajrccm-conference.2017.195.1 MeetingAbstracts.A3194. The full citation for the abstract is as follows: Ferguson GT, Mansur A, Jacobs J, Hebert J, Clawson C, Tao W, Wu Y, Goldman M on behalf of the GREGALE study investigators. Functionality, reliability, and performance of an accessorized pre-filled syringe with home-administered subcutaneous benralizumab for adult patients with severe asthma. Am J Respir Crit Care Med. 2017;195:A3194 (Abstract 6008).

\section{Disclosure}

GTF received consultancy fees from AstraZeneca, Boehringer Ingelheim, and Pearl Therapeutics; served on board or advisory committees for AstraZeneca, Pearl Therapeutics, and Novartis; received research support from AstraZeneca, Boehringer Ingelheim, Pearl Therapeutics, Sunovion, Novartis, and Theravance; and received research grants from AstraZeneca to conduct the GREGALE trial. AHM received speaker fees and payment (including gifts or "inkind" compensation) through attending advisory board meetings of various companies, including Novartis, Roche, AstraZeneca, NAPP, and Boehringer Ingelheim; received educational grants for service development from Novartis; and participated in Phase IIb and III clinical trials with AstraZeneca, Novartis, and Roche. JSJ served as a speaker/ teacher for Shire and Teva; served as a clinical investigator for CSL Behring, Genentech, Regeneron, Sanofi, Shire, and Teva; acted on advisory committees for CSL Behring, Pharming Group, and Regeneron; and served as an independent contractor for Genentech, CSL Behring, Regeneron, and Teva. JH served as a consultant for Novartis, Merck, Teva, CSL Behring, Baxter, and Shire; was a conference speaker for Merck, Novartis, Shire, Meda, and CSL Behring; and served as an investigator in clinical trials for Merck, Novartis, Stallergenis, GlaxoSmithKline, Boehringer Ingelheim, CSL Behring, and DBV. CC is an employee of MedImmune and holds stock in AstraZeneca. WT, YW, and MG are employees of AstraZeneca. The authors report no other conflicts of interest in this work.

\section{References}

1. Chung KF, Wenzel SE, Brozek JL, et al. International ERS/ATS guidelines on definition, evaluation and treatment of severe asthma. Eur Respir J. 2014;43:343-373.

2. To T, Stanojevic S, Moores G, et al. Global asthma prevalence in adults: findings from the cross-sectional world health survey. BMC Public Health. 2012;12:204

3. Peters SP, Ferguson G, Deniz Y, Reisner C. Uncontrolled asthma: a review of the prevalence, disease burden and options for treatment. Respir Med. 2006;100:1139-1151.

4. Price D, Wilson AM, Chisholm A, et al. Predicting frequent asthma exacerbations using blood eosinophil count and other patient data routinely available in clinical practice. J Asthma Allergy. 2016;9:1-12.

5. Talini D, Novelli F, Bacci E, et al. Sputum eosinophilia is a determinant of $\mathrm{FEV}_{1}$ decline in occupational asthma: results of an observational study. BMJ Open. 2015;5:e005748.

6. Belda J, Parameswaran K, Lemiere C, Kamada D, O’Byrne PM, Hargreave FE. Predictors of loss of asthma control induced by corticosteroid withdrawal. Can Respir J. 2006;13:129-133.

7. Benralizumab (FASENRA ${ }^{\mathrm{TM}}$ ) Prescribing Information; 2017. Available from: https://www.accessdata.fda.gov/drugsatfda_docs/ label/2017/761070s000lbl.pdf. Accessed January 10, 2018.

8. Bleecker ER, FitzGerald JM, Chanez P, et al. Efficacy and safety of benralizumab for patients with severe asthma uncontrolled with highdosage inhaled corticosteroids and long-acting $\beta_{2}$-agonists (SIROCCO): a randomised, multicentre, placebo-controlled phase 3 trial. Lancet. 2016;388:2115-2127.

9. Ferguson GT, FitzGerald JM, Bleecker ER, et al. Benralizumab for patients with mild to moderate, persistent asthma (BISE): a randomised, double-blind, placebo-controlled, phase 3 trial. Lancet Respir Med. 2017;5:568-576.

10. FitzGerald JM, Bleecker ER, Nair P, et al. Benralizumab, an antiinterleukin-5 receptor $\alpha$ monoclonal antibody, as add-on treatment for patients with severe, uncontrolled, eosinophilic asthma (CALIMA): a randomised, double-blind, placebo-controlled phase 3 trial. Lancet. 2016;388:2128-2141.

11. Goldman M, Hirsch I, Zangrilli JG, Newbold P, Xu X. The association between blood eosinophil count and benralizumab efficacy for patients with severe, uncontrolled asthma: subanalyses of the Phase III SIROCCO and CALIMA studies. Curr Med Res Opin. 2017;3(9):1605-1613.

12. Huynh TK, Ostergaard A, Egsmose C, Madsen OR. Preferences of patients and health professionals for route and frequency of administration of biologic agents in the treatment of rheumatoid arthritis. Patient Prefer Adherence. 2014;8:93-99.

13. Stoner KL, Harder H, Fallowfield LJ, Jenkins VA. Intravenous versus subcutaneous drug administration. Which do patients prefer? A systematic review. Patient. 2015;8(2):145-153.

14. Sacha G, Rogers JA, Miller RL. Pre-filled syringes: a review of the history, manufacturing and challenges. Pharm Dev Technol. 2015;20:1-11.

15. Romacker M, Schoenknecht T, Forster R. Prefilled syringes: the container of choice for today's injectables. ONDrug Delivery. 2008:4-5. 
16. Ferguson GT, Mansur A, Jacobs J, et al. Functionality, reliability, and performance of an accessorized pre-filled syringe with home administered subcutaneous benralizumab for adult patients with severe asthma [abstract]. Am J Respir Crit Care Med. 2017;195:A3194.

17. Juniper EF, Bousquet J, Abetz L, Bateman ED, Committee G. Identifying "well-controlled" and "not well-controlled" asthma using the Asthma Control Questionnaire. Respir Med. 2006;100:616-621.
18. Stelara [package insert]. Horsham, PA: Janssen Biotech Inc.; 2012.

19. Nair P, Wenzel S, Rabe KF, et al. Oral glucocorticoid-sparing effect of benralizumab in severe asthma. N Engl J Med. 2017;376:2448-2458.

20. FitzGerald JM, Bleecker ER, Menzies-Gow A, et al. Predictors of enhanced response with benralizumab for patients with severe asthma: pooled analysis of the SIROCCO and CALIMA studies. Lancet Respir Med. 2018;6:51-64. 


\section{Supplementary material}

\section{Principal study investigators}

The following principal investigators participated in the study:

\section{Canada}

Jaime Del Carpio; Cheema Research, Inc.: Amarjit Cheema; Recherche Clinique Sigma: Guy Chouinard; Dynamik Research, Inc.: Anthony Dowell; Medical Centre, Primary Care Lung Clinic: Anthony D'Urzo; The Chest Clinic: Francis Ervin; Lung Centre: John Fitzgerald; Anil Gupta; Place de la Cite-Tour Belcou: Jacques Hebert; CIC Mauricie, Inc.: Pierre-Alain Houle; Xceed Clinical Research, Inc.: Sohail
Khattak; Burlington Lung Clinic: Patrick Killorn; Hospital Sacre Coeur: Catherine Lemiere; Rajesh Mainra; Topstone Clinical Research: Jean Oosthuizen, Deepen Patel; Clinique de Pneumologie et de Sommeil de Lanaudiere: Bonavuth Pek; Brandie Walker.

\section{USA}

IPS Research Co: Jeremy Cole; Central Florida Pulmonary Group: Kevin DeBoer; Allergy and Asthma Research Center PA: Joseph Diaz; The Asthma and Allergy Center PC: Linda Ford; Clinical Research Institute: Philip Halverson; Allergy \& Asthma Med Group Diablo Valley: Joshua Jacobs; The Clinical Research Center, LLC: Phillip Korenblat; Allianz Research Institute, Inc.: David Pham.

\section{Publish your work in this journal}

The Journal of Asthma and Allergy is an international, peer-reviewed open access journal publishing original research, reports, editorials and commentaries on the following topics: Asthma; Pulmonary physiology; Asthma related clinical health; Clinical immunology and the immunological basis of disease; Pharmacological interventions and new therapies. This journal is included in PubMed. The manuscript management system is completely online and includes a very quick and fair peer-review system, which is all easy to use. Visit http://www. dovepress.com/testimonials.php to read real quotes from published authors. 